\title{
The Dose Effect of Whey Protein on Glycemic Control in Adults with Insulin Resistance
}

\author{
Todd Castleberry ${ }^{1,2,{ }^{*} \text {, Christopher Irvine }}{ }^{1,3}$, Ryan Gordon ${ }^{1}$, Matthew Brisebois ${ }^{1,4}$, \\ Sarah Deemer ${ }^{1,5}$, Aubrien Henderson ${ }^{1}$, Matthew Sokoloski ${ }^{1}$, Vic Ben-Ezra ${ }^{1}$ \\ ${ }^{1}$ School of Health Promotion \& Kinesiology, Texas Woman's University, Denton, USA \\ ${ }^{2}$ Department of Kinesiology, Louisiana Tech University, Ruston, USA \\ ${ }^{3}$ Department of Health and Human Performance, Rocky Mountain College, Billings, USA \\ ${ }^{4}$ Department of Human Performance and Health, University of South Carolina Upstate, Spartanburg, USA \\ ${ }^{5}$ Department of Kinesiology, Health Promotion, and Recreation, University of North Texas, Denton, USA
}

Email address:

toddc@latech.edu (T. Castleberry)

${ }^{*}$ Corresponding author

\section{To cite this article:}

Todd Castleberry, Christopher Irvine, Ryan Gordon, Matthew Brisebois, Sarah Deemer, Aubrien Henderson, Matthew Sokoloski, Vic BenEzra. The Dose Effect of Whey Protein on Glycemic Control in Adults with Insulin Resistance. International Journal of Food Science and Biotechnology. Vol. 5, No. 4, 2020, pp. 52-57. doi: 10.11648/j.ijfsb.20200504.12

Received: October 9, 2020; Accepted: October 21, 2020; Published: October 30, 2020

\begin{abstract}
Whey protein coupled with a glucose challenge increases insulin secretion and may decrease glucose responses in people with pre-diabetes and type 2 diabetes. These responses may be attributed to whey protein's effect on the incretins glucagon-like peptide-1 (GLP-1) and glucose dependent insulinotropic polypeptide (GIP). The purpose of this study was to examine the effect of various doses of whey protein on postprandial glycemic control and incretin responses. Participants with insulin resistance $\left(n=9\right.$, mean $\pm \mathrm{SD}$; age: $64.3+8.1 \mathrm{yrs}$; BMI: $29.4+6.0 \mathrm{~kg} / \mathrm{m}^{2}$; fasting plasma glucose: $6.9+1.2 \mathrm{mmol} / \mathrm{l}$; HbA1c: $6.4+0.6 \%$ ) completed three randomized treatments. Treatment 1 included $250 \mathrm{ml}$ water $+20 \mathrm{~g}$ whey protein $\left(\mathrm{T}_{1}\right)$, and treatment 2 included $250 \mathrm{ml}$ water $+30 \mathrm{~g}$ whey protein $\left(\mathrm{T}_{2}\right)$. The control treatment included $250 \mathrm{ml}$ water $(\mathrm{CON})$. Each treatment was followed by a $50 \mathrm{~g}$ oral glucose tolerance test. Incremental area under the curve (iAUC) for insulin increased from CON to $\mathrm{T}_{1}(P<0.01,45.5 \%)$, CON to $\mathrm{T}_{2}(P<0.01,61.0 \%)$, and $\mathrm{T}_{1}$ to $\mathrm{T}_{2}(P<0.01,28.5 \%)$, with a significant decrease in postprandial AUC for glucose with $\mathrm{T}_{2}(P=0.04,-41.2 \%)$. Neither GIP nor GLP-1 ${ }_{\mathrm{i}} \mathrm{AUC}$ increased with $\mathrm{T}_{1}$ or $\mathrm{T}_{2}$ compared to CON. However, postprandial glucose ${ }_{i} \mathrm{AUC}$ was significantly reduced for $\mathrm{T}_{2}$ compared to $\mathrm{CON}(P=0.04,-41.2 \%)$. There was a dose effect of whey protein on plasma insulin with a significant decrease in postprandial glucose ${ }_{i}$ AUC following $T_{2}$. Thirty grams of a whey protein preload may be adequate to provide postprandial glycemic improvements in the disease management of type 2 diabetes or pre-diabetes
\end{abstract}

Keywords: Diabetes, Pre-diabetes, GIP, GLP-1, Glucose, Glucagon

\section{Introduction}

Insulin resistance (IR) is defined as an impairment in glucose homeostasis resulting from decreased insulin sensitivity in multiple body tissues including skeletal muscle and liver [1]. IR leads to increased blood glucose concentrations, resulting in many individuals having developed pre-diabetes or type 2 diabetes. There are many strategies used to treat IR including a combination of medications, diet, exercise, and weight loss [2]. Incretin- based therapies are also commonly prescribed to patients with IR to decrease chronically high blood glucose and high levels of glycated hemoglobin (HbA1c) [3]. The incretin hormones glucose-dependent insulinotropic polypeptide (GIP) and glucagon-like peptide-1 (GLP-1) account for approximately $50-70 \%$ of insulin secretion following nutrient ingestion in healthy individuals [4]; however, the incretin response following nutrient intake is reduced in people with type 2 diabetes [5]. Recent investigations have implemented whey protein as a potential treatment for the 
management of IR [6, 7]. Whey protein augments insulin secretion through an increase of the incretin hormones in people with type 2 diabetes [8], while subsequently decreasing blood glucose concentrations in both healthy [9], and type 2 diabetes [10].

Decreases in glucose area under the curve (AUC) are evident when $50 \mathrm{~g}$ of whey protein is consumed $30 \mathrm{~min}$ prior to nutrient ingestion [10]. Recent literature has suggested smaller doses of whey protein such as $15 \mathrm{~g}$ for those with type 2 diabetes [7] and $20 \mathrm{~g}$ for obese males [6], consumed prior to meal ingestion can reduce postprandial glucose. In healthy individuals, there is a dose dependent postprandial increase in insulin, with a subsequent decrease in glucose following whey protein ingestion of 5-20 g [11], 10-40 $\mathrm{g}$ [9], and 10-20 g [12]. However, it is unknown if there is a similar dose effect of whey protein in individuals with IR. Therefore, the purpose of this study was to examine the effect of $20 \mathrm{~g}$ $\left(\mathrm{T}_{1}\right)$ and $30 \mathrm{~g}\left(\mathrm{~T}_{2}\right)$ of whey protein isolate ingested $30 \mathrm{~min}$ prior to a $50 \mathrm{~g}$ oral glucose tolerance test (OGTT) on plasma glucose, insulin, C-peptide, GIP, GLP-1 and glucagon responses in individuals with IR. Our hypothesis was that both $T_{1}$ and $T_{2}$ would result in an increase in insulin secretion and a decrease in plasma glucose concentrations, with $T_{2}$ producing the greatest improvements.

\section{Materials and Methods}

\subsection{Study Population}

Nine sedentary male participants with IR were recruited to participate in this study $(n=9$, mean $\pm \mathrm{SD}$; age: $64.3+8.1$ yrs; BMI: $29.4+6.0 \mathrm{~kg} / \mathrm{m}^{2}$; fasting plasma glucose: $6.9+1.2$ mmol/1; HbA1c: $6.4+0.6 \%$ ). Sedentary was defined by $<150$ min of physical activity per week. Participants taking any medications known to affect rate of gastric emptying or hypoglycemic agents other than sulfonylurea or metformin were excluded. Participants completed a preliminary blood draw that was analyzed for fasting plasma glucose and $\mathrm{HbA1c}$ to determine qualification for the study based on American Diabetes Association guidelines [13]. Participants with a fasting plasma glucose $>5.56 \mathrm{mmol}$ or $\mathrm{HbA} 1 \mathrm{c}>5.7 \%$ were selected. This study was approved by the Texas Woman's University Institutional Review Board.

\subsection{Anthropometrics}

Body composition was measured using dual-energy $\mathrm{x}$-ray absorptiometry (DXA; Lunar Prodigy; GE Healthcare, Madison, WI). Height, weight, and body mass index (BMI) were determined. Height was measured using a stadiometer (Perspective Enterprises; Kalamazoo, MI) and weight was measured to the nearest $0.1 \mathrm{~kg}$ using a digital scale (Tanita Corp.; Arlington Heights, IL).

\subsection{Study Design}

Participants completed three randomized treatments that consisted of consuming: $250 \mathrm{ml}$ of water $(\mathrm{CON}), 250 \mathrm{ml}$ of water $+20 \mathrm{~g}$ whey protein $\left(\mathrm{T}_{1}\right)$, and $250 \mathrm{ml}$ of water $+30 \mathrm{~g}$ whey protein $\left(\mathrm{T}_{2}\right)$, followed by a $50 \mathrm{~g}$ OGTT. The whey protein (Isopure Whey Protein Isolate, Nature's Best, Hauppauge, New York, United States) and CON were consumed as a preload ( $30 \mathrm{~min}$ prior to the $50 \mathrm{~g}$ OGTT) and treatments were separated by a minimum of seven days. Participants recorded a three-day diet log preceding each treatment, with the dinner meal the night prior to each OGTT kept consistent for macronutrient composition and timing.

\subsection{Oral Glucose Tolerance Test (OGTT)}

Participants arrived at the laboratory between 0500 and $0700 \mathrm{hrs}$ following a $10 \mathrm{hr}$ fast to complete a 50g OGTT. A venous catheter was placed in an antecubital vein and the participant rested for $5 \mathrm{~min}$ before the first blood draw (baseline). A $0.9 \%$ saline solution with a $1 / 5$ s drip rate was used to keep the line patent. Following the first blood draw, participants consumed a designated whey protein preload corresponding to $\mathrm{T}_{1}, \mathrm{~T}_{2}$, or CON. Another blood draw was taken $30 \mathrm{~min}$ after the preload, which was immediately followed by the $50 \mathrm{~g}$ OGTT. Additional samples were collected at 15, 30, 60, 90, 120, and $150 \mathrm{~min}$ after the consumption of the OGTT beverage (Trutol Dextrose, ThermoFisher Scientific, Waltham, United States). Blood samples were collected into $4 \mathrm{ml}$ EDTA tubes containing 1.25 Pefabloc/ml of blood (Roche Diagnostics, Mannheim, Germany), $5 \mu$ l Protease Inhibitor/ml of blood (EMD Millipore Corporation, Billerica, Massachusetts, United States), and $5 \mu 1$ Protease Cocktail $/ \mathrm{ml}$ of blood, and Protease Cocktail/ml of blood (EMD Millipore Corporation, Billerica, Massachusetts, United States). Blood samples were immediately centrifuged at $3000 \mathrm{rpm}$ for $10 \mathrm{~min}$ at $10^{\circ} \mathrm{C}$. Plasma was aliquoted into cryogenic vials and stored at $80^{\circ} \mathrm{C}$ until analysis. Samples thawed for one hour prior to plasma analysis of glucose, insulin, C-peptide, GIP, GLP-1 and glucagon. Plasma glucose was analyzed using a YSI 2900D glucose analyzer (Yellow Spring Inc, Yellow Springs, Ohio, United States). Plasma hormone concentrations of Cpeptide, GIP, GLP-1, insulin, and glucagon were analyzed using a Luminex Human Metabolic Hormone multiplex assay (HMHEMAG-34, EMD Millipore, Billerica, MA). Twenty-five $\mu 1$ of each sample were analyzed in duplicate.

\subsection{Statistical Analysis}

Incremental area under the curve $\left({ }_{\mathrm{i}} \mathrm{AUC}\right)$ was calculated using the trapezoidal method. Two areas were calculated, ${ }_{\mathrm{i}} \mathrm{AUC}$ (baseline to 150) and postprandial ${ }_{\mathrm{i}} \mathrm{AUC}(0-150)$ to analyze the responses of whey protein and the OGTT alone. Repeated-measures analysis of variance (RM ANOVA) was used to determine significant differences in ${ }_{i} A U C$ for all dependent variables. The differences at each time-point across treatments were also analyzed by RM ANOVA. Statistical significance was set at $P<.05$. If results were significant, a Bonferroni post-hoc test was used for pairwise comparisons. The statistical analysis for glucagon was $(n=6)$ due to low values outside the range of the kit. 


\section{Results}

\subsection{Participant Characteristics}

A total of nine participants completed the study. Table 1 displays participant descriptive characteristics. There were no significant differences in baseline fasting values between the three treatments (see Figure 3).

Table 1. Participant Characteristics.

\begin{tabular}{lll}
\hline Age $(\mathrm{y})$ & 64.3 & 8.1 \\
Height $(\mathrm{m})$ & 1.68 & 0.1 \\
Weight $(\mathrm{kg})$ & 83.21 & 20.3 \\
BMI $\left(\mathrm{kg} / \mathrm{m}^{2}\right)$ & 29.41 & 6.0 \\
Body Fat $(\%)$ & 42.51 & 7.8 \\
HbA1c (mmol/mol) & 45.8 & 4.3 \\
HbA1c (\%) & 6.37 & 0.6 \\
Fasting Plasma Glucose (mmol) & 6.85 & 1.2 \\
\hline
\end{tabular}

Data are presented as mean $\pm \mathrm{SD}$.

\subsection{Incremental AUC}

(A)

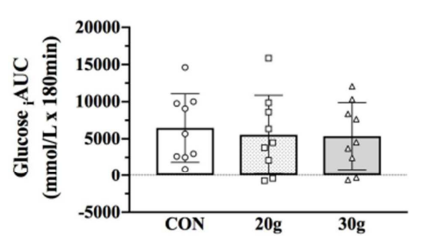

(C)

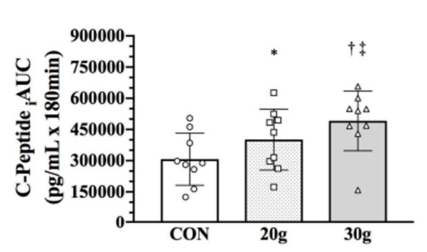

(E)

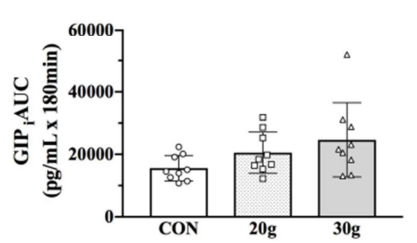

(B)

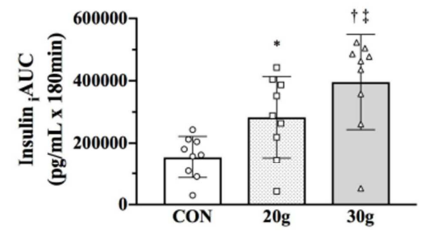

(D)

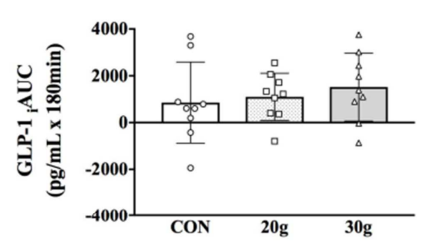

(F)

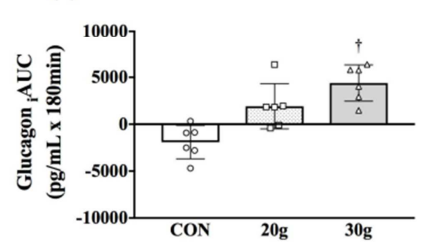

Figure 1. ${ }_{i} A U C$ of $C O N, T_{1}$, and $T_{2}$. For every time-point, plasma was analyzed for glucose (A), insulin (B), C-peptide (C), GLP-1 (D), GIP (E), and glucagon $(F)$. * represents significant differences for $T_{1}$ compared to CON. + represents significant differences for $T_{2}$ compared to CON. Circles: CON, squares: $T_{1}$, triangles: $T_{2} . \neq$ represents significant differences for $T_{2}$ compared to $T_{1}$.

Glucose ${ }_{\mathrm{i}} \mathrm{AUC}$ was not different between the 3 treatments (Figure 1A). Insulin ${ }_{i} \mathrm{AUC}$ (Figure 1B) was significantly greater in $\mathrm{T}_{1}$ compared to $\mathrm{CON}(P<0.01,45.5 \%), \mathrm{T}_{2}$ compared to $\mathrm{CON}(P<0.01,61.0 \%)$, and the $\mathrm{T}_{2}$ compared to
$\mathrm{T}_{1}(P<0.01,28.5 \%)$. C-peptide ${ }_{\mathrm{i}} \mathrm{AUC}$ (Figure 1C) was greater in $\mathrm{T}_{1}$ compared to $\mathrm{CON}(P<0.01,23.5 \%)$ and $\mathrm{T}_{2}$ compared to CON $(P<0.01,37.5 \%)$. Glucagon ${ }_{i} A U C$ (Figure $\left.1 \mathrm{~F}\right)$ was greater in $\mathrm{T}_{2}$ compared to $\mathrm{CON}(P<0.01,143 \%)$. There were no significant differences in ${ }_{\mathrm{i}} \mathrm{AUC}$ for total GLP-1 (Figure 1D) or GIP (Figure 1E).

\subsection{Postprandial ${ }_{i} A U C$}

Glucose postprandial ${ }_{\mathrm{i}} \mathrm{AUC}$ (Figure 2A) was significantly reduced following $\mathrm{T}_{2}$ compared to $\mathrm{CON}(P=0.04,-41.2 \%)$ and insulin postprandial ${ }_{\mathrm{i}} \mathrm{AUC}$ (Figure $2 \mathrm{~B}$ ) was significantly higher for $\mathrm{T}_{2}$ compared to $\mathrm{CON}(P=0.042,38 \%)$. GIP postprandial ${ }_{\mathrm{i}} \mathrm{AUC}$ (Figure $2 \mathrm{E}$ ) was significantly decreased for $\mathrm{T}_{1}$ compared to $\mathrm{CON}(P=0.021,-27.2 \%)$, and $\mathrm{T}_{2}$ compared to $\operatorname{CON}(P=0.01,-20.4 \%)$ with no significant changes for GLP-1 across all treatments. The glucagon postprandial ${ }_{i} A U C$ (Figure 2F) was lower for both $T_{1}$ compared to $\mathrm{CON}(P=0.01,-79.9 \%)$, and $\mathrm{T}_{2}$ compared to CON $(P=0.032,-76.0 \%)$.
(A)

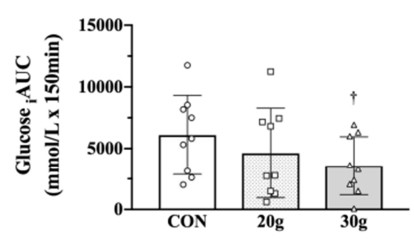

(C)

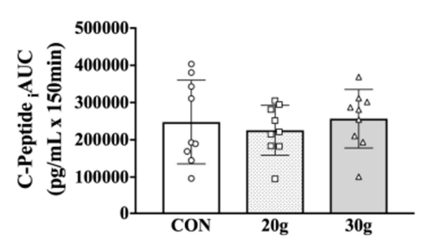

(E)



(B)

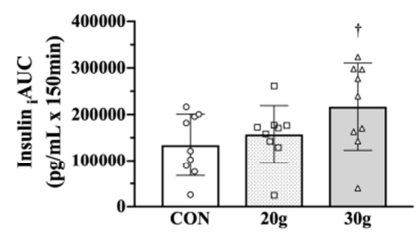

(D)

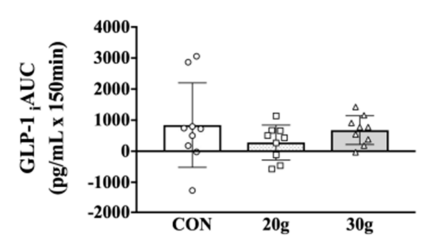

Figure 2. Postprandial ${ }_{i} A U C$ for $C O N, T_{1}$, and $T_{2}$. Calculations were made for glucose (A), insulin (B), C-peptide (C), GLP-1 (D), GIP (E), and glucagon $(F)$. * represents significant differences for $T_{1}$ compared to $C O N . \dagger$ represents significant differences for $T_{2}$ compared to CON.

\subsection{Time-point}

Glucose (Figure 3A) was not different between treatments for any time-points. Insulin (Figure 3B) was significantly increased at $\min 30$ for $\mathrm{T}_{2}$ compared to $\mathrm{CON}(P<0.01)$ and was continuously increased through $\min 90$. C-peptide (Figure 3C) was elevated in a similar manner as insulin 
without significant differences between treatments. GLP-1 (Figure 3D) increased following $\mathrm{T}_{1}$ compared to $\mathrm{CON}$ at min 60 and $\min 120(P=0.02 ; P=0.02)$. GLP-1 was also elevated for $\mathrm{T}_{2}$ at $\min 90$ and 120 compared to $\mathrm{CON}(P<0.01$, $P<0.01$ ). GIP (Figure 3E) was not different between treatments for any time-points. Glucagon (Figure 3F) increased following $T_{1}$ and $T_{2}$ consumption compared to CON $(P=0.04, P=0.03)$ respectively. Glucagon remained elevated for $\mathrm{T}_{2}$ compared to $\mathrm{CON}$ through $\min 90$ before returning to baseline values.
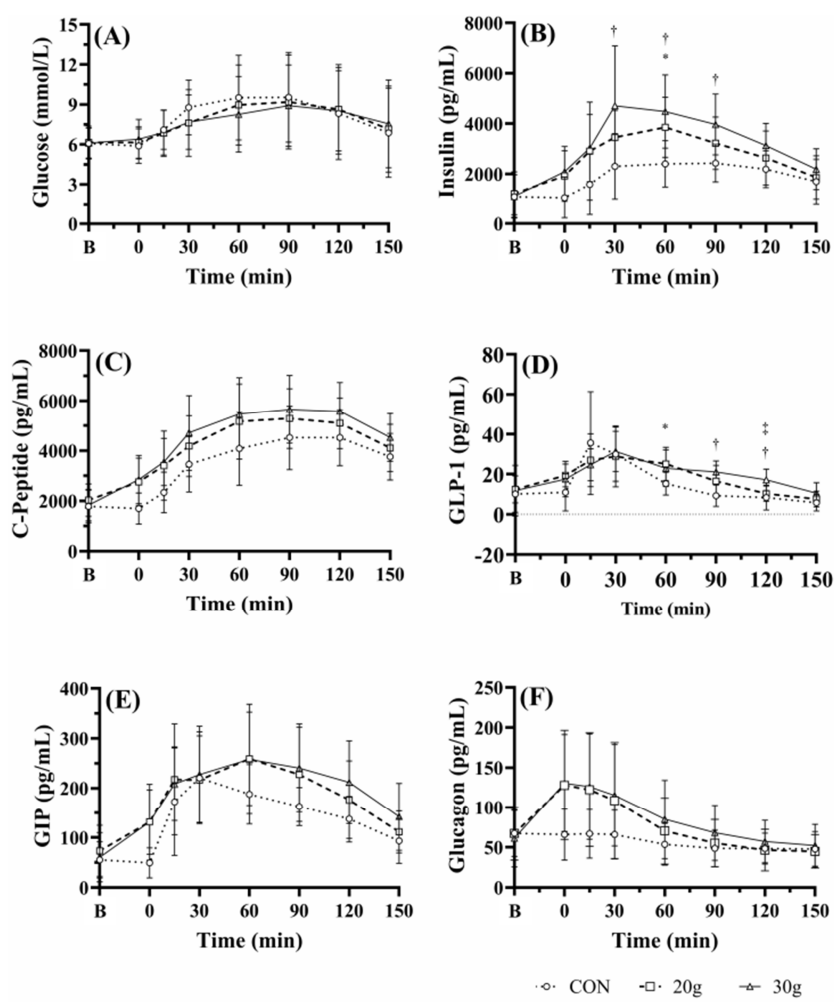

Figure 3. Treatments of CON, $T_{1}$, and $T_{2}$. For every time-point, plasma was analyzed for glucose (A), insulin (B), C-peptide (C), GLP-1 (D), GIP (E), and glucagon $(F)$. * represents significant differences for $T_{1}$ compared to CON. † represents significant differences for $T_{2}$ compared to CON. Circles: CON, squares: $T_{1}$, triangles: $T_{2}+\neq$ represents significant differences for $T_{2}$ compared to $T_{1}$.

\section{Discussion}

In the current experiment, there was no decrease in glucose iAUC; however, postprandial ${ }_{\mathrm{i}} \mathrm{AUC}$ for glucose was significantly decreased following $\mathrm{T}_{2}$ of whey preload as shown in Figure 2A. Previous literature has reported decreases in glucose concentration following similar doses of whey protein in obese males and those with insulin resistance $[6,7]$. One study examining a $20 \mathrm{~g}$ whey protein $15 \mathrm{~min}$ preload observed decreases in postprandial glucose concentrations [6]. King and colleagues also observed a decrease in postprandial glucose AUC following $15 \mathrm{~g}$ of whey consumed with a mixed meal in men with IR [7]. Whey protein quantities of $40 \mathrm{~g}$ and higher have also led to increased insulin and decreased plasma glucose responses in individuals with type 2 diabetes $[10,14]$ and prediabetes
[15]. Jakubowicz et al. (2014) reported a decrease in both peak glucose and glucose $180 \mathrm{~min}$ AUC following the ingestion of $50 \mathrm{~g}$ of whey protein mixed with $250 \mathrm{ml}$ of water as a preload, prior to a high glycemic breakfast in individuals with type 2 diabetes [8]. Although the current study did not examine changes in peak glucose for $T_{2}$, there was an equivalent increase in plasma insulin using a similar research design as Jakubowicz and colleagues with a decrease in glucose postprandial ${ }_{\mathrm{i}} \mathrm{AUC}[8]$.

The decrease in postprandial ${ }_{i} \mathrm{AUC}$ for glucose can be attributed to the increase in insulin concentration 30 minutes following $T_{1}$ and $T_{2}$, prior to glucose ingestion (Figure 2B). Insulin and $\mathrm{C}$-peptide complete ${ }_{\mathrm{i}} \mathrm{AUC}$ (Figure 1B, 1C) appear to have a concomitant rise with $\mathrm{T}_{1}$ and $\mathrm{T}_{2}$ whey protein ingestion. Approximately $50-70 \%$ of insulin secretion is stimulated by incretins [4]. Although whey protein has been reported to stimulate release of GLP-1 and GIP, the current study did not observe changes in complete ${ }_{\mathrm{i}} \mathrm{AUC}$ (Figure 1D, 1E). Conversely, postprandial ${ }_{i} A U C$ for GIP was reduced following $T_{1}$ and $T_{2}$ of whey protein ingestion (Figure $2 E$ ). However, as shown in Figure 3E, postprandial ${ }_{\mathrm{i}} \mathrm{AUC}$ for GIP did in fact increase immediately following the ingestion of whey. Individuals with insulin resistance are reported to have an impaired incretin effect [16]. This could explain the absence of a rise in GLP-1 (Figure 1D) and GIP (Figure 1E).

Insulin secretion may also be increased directly through amino acids. Certain positively charged amino acids are suggested to potentiate insulin secretion through an increase in depolarization of pancreatic beta cells [17, 18]. Arginine stimulates a calcium influx that depolarize the voltage gated channels, leading to insulin secretion [17]. L-arginine is known to have a similar effect by increasing intracellular calcium uptake, resulting in insulin secretion [18]. Studies have also reported branched-chain amino acids such as leucine and isoleucine may have a direct effect on insulin secretion through pancreatic beta cells $[19,20]$. Another potential reason for the increase in insulin without a subsequent decrease in plasma glucose concentration could be the inhibition of glucose uptake in skeletal muscle. Protein ingestion has been suggested to induce skeletal muscle insulin resistance in mice by inhibiting AKT via the mTOR pathway [21]. The current study did not examine skeletal muscle activity.

Lastly, Figure $1 \mathrm{~F}$ illustrates an acute increase in glucagon following the ingestion of whey protein. Insulin suppresses hepatic glucose production by more than $50 \%$, while also inhibiting glucagon [22, 23]. Glucagon is also inhibited by GLP-1. Conversely, glucagon is enhanced through increases in GIP [24]. Based on Figure 1D and 1E, GLP-1 or GIP do not seem to have an influence on the increased glucagon complete ${ }_{i} A U C$ (Figure 1F). This is a similar result to Frid et al. where no changes in GLP-1 following $27.6 \mathrm{~g}$ of whey consumption in individuals with type 2 diabetes were observed [25]. However, Frid and colleagues did observe an increase in GIP ${ }_{i}$ AUC [25]. A decrease in postprandial ${ }_{\mathrm{i}} \mathrm{AUC}$ for glucagon was observed in the present study (Figure 2F), but this was due to the initial rise following the whey protein preload. Based on the complete ${ }_{\mathrm{i}} \mathrm{AUC}$ for glucose (Figure 1A), insulin (Figure 1B), and 
glucagon (Figure 1F), the authors speculate glucagon may play a stronger role than expected in increasing plasma glucose than insulin has on lowering plasma glucose.

\section{Conclusion}

The current study found that whey protein doses of $20 \mathrm{~g}$ and $30 \mathrm{~g}$ administered $30 \mathrm{~min}$ prior to an OGTT resulted in a concomitant rise in plasma insulin complete ${ }_{\mathrm{i}} \mathrm{AUC}$; however, plasma glucose was unaffected. Previous literature suggests $40 \mathrm{~g}$ and $50 \mathrm{~g}$ of whey protein can provide glycemic benefit in individuals with IR [9, 10]. Contradictory to previous studies examining lower doses, the results of the current study suggest that $20 \mathrm{~g}$ and $30 \mathrm{~g}$ of whey protein may not be beneficial in individuals with IR. Whey protein may provide benefits in healthy individuals but there may other mechanisms inhibiting the effectiveness for individuals with IR. Neither $T_{1}$ nor $T_{2}$ of whey protein may be adequate to provide glycemic improvement in the disease management of pre-diabetes or type 2 diabetes. More research is needed to provide a greater understanding of the effects whey protein has on individuals with IR. An advantage of consuming whey preload is delaying gastric emptying in individuals with type 2 diabetes [10]. In the current study, whey protein consumed as a preload does not appear to be the most ideal strategy. However, as shown with postprandial ${ }_{\mathrm{i}} \mathrm{AUC}$ for glucose, this technique appeared to have beneficial results from the preprandial rise in insulin following $\mathrm{T}_{2}$ of whey consumption.

\section{Limitations}

The sample size of the present study was too small to differentiate between individuals with pre-diabetes $(n=4)$ and type 2 diabetes $(n=5)$. However, both groups appeared to have similar results. Another limitation is the use of only two separate doses of whey protein. Previous literature has suggested larger doses are beneficial in the population recruited for this study. The novelty of this study was in determining if lower doses were more effective.

\section{Acknowledgements}

TC, CI, SD, and VB designed the study. TC, CI, RG, MB, and $\mathrm{SD}$ recruited participants and collected data. TC, CI, RG, and $\mathrm{AH}$ analyzed the blood samples. TC and $\mathrm{MB}$ analyzed the data. TC, CI, RG, MB, SD, MS and VB drafted the manuscript. All of the authors approved the final version of the manuscript.

\section{References}

[1] Rogowicz-Frontczak, A., Majchrzak, A., ZozulinkaZoilkiewicz, D. (2017). Insulin resistance in endocrine disorders-treatment options. Endokrynol Pol; 68 (3): 334-342.

[2] Olokoba, A. B., Obateru, O. A., Olokoba, L. B. (2012) Type 2 diabetes mellitus: A review of current trends. Oman Medical Journal Jul; 27 (4): 269-273.
[3] Russell, S. (2013). Incretin-based therapies for type 2 diabetes mellitus: a review of direct comparisons of efficacy, safety and patient satisfaction. Int J Clin Pharm Apr; 35 (2): 159-172.

[4] Holst, J., \& Deacon, C. (2013). Is there a place for incretin therapies in obesity and prediabetes? Trends in Endocrinology and Metabolism, 24 (3), 145-152.

[5] Bagger, J., Knop, F., Lund, A., Vestergaard, H., Holst, J., \& Visboll, T. (2011). Impaired regulation of the incretin effect in patients with type 2 diabetes. Journal of Clinical Endocrinology and Metabolism, 3 (96), 737-745.

[6] Allerton, D., Rumbold, P., West, D., \& Stevenson, E. (2019). Effect of supplemental whey protein timing on postprandial glycaemia in centrally-obese males. British Journal of Nutrition, 121 (6), 637-646.

[7] King, D. G., Walker, M., Campbell, M. D., Breen, L., Stevenson, E. J., \& West, D. J. (2018). A small dose of whey protein co-ingested with mixed-macronutrient breakfast and lunch meals improved postprandial glycemia and suppresses appetite in men with type 2 diabetes: a randomized controlled trial. American Journal of Clinical Nutrition, 107 (4), 550-557.

[8] Jakubowicz, D., Froy, O., Ahrén, B., Boaz, M., Landau, Z., Bar-Dayan, Y., Ganz, T., Barnea, M., \& Wainstein, J. (2014). Incretin, insulinotropic and glucose-lowering effects of whey protein pre-load in type 2 diabetes: A randomised clinical trial. Diabetologia, 57 (9), 1807-11.

[9] Akhavan, T., Luhovyy, B., Brown, P., Cho, C., \& Anderson G. (2010). Effect of premeal consumption of whey protein and its hydrolysate on food intake and postmeal glycemia and insulin responses in young adults. American Journal of Clinical Nutrition, 91 (4), 966-75. doi: 10.3945/ajen.2009.28406.

[10] Ma, J., Jesudason, D. R., Stevens, J. E., Keogh, J. B., Jones K. L., Clifton, P. M., Horowitz, M., \& Rayner, C. K. (2015). Sustained effects of a protein 'preload' on glycaemia and gastric emptying over 4 weeks in patients with type 2 diabetes: A randomized clinical trial. Diabetes Research Clinical Practice, 108 (2), e31-e34.

[11] Petersen, B. L., Ward, L. S., Bastian, E. D., Jenkins, A. L., Campbell, J., \& Vuksan, V. (2009). A whey protein supplement decreases post-prandial glycemia. Nutrition Journal, 16 (8), 47.

[12] Akhavan, T., Luhovyy, B., Panahi, S., Kubant, R., Brown, P., \& Anderson, G. (2014). Mechanism of action of pre-meal consumption of whey protein on glycemic control in young adults. Journal of Nutrition Biochemistry, 25 (1), 36-43. doi: 10.1016/j.jnutbio.2013.08.012.

[13] American Diabetes Association. (2018). Classification and diagnosis of diabetes: Standards of medical care in diabetes2018. Diabetes Care 41 (1): S13-S27.

[14] Ma, J., Stevens, J. E., Cukier, K., Maddox, A. F., Wishart, J. M., Jones, K. L., Clifton, P. M., Horowitz, M., \& Rayner, C. K. (2009). Effects of a protein preload on gastric emptying, glycemia, and gut hormones after a carbohydrate meal in dietcontrolled type 2 diabetes. Diabetes Care, 32 (9), 1600-1602.

[15] Hoefle, A., Bangert, A., Stamfort, A., Gedrich, K., Rist, M., Lee, Y., Skurk, T., \& Daniel, H. (2015). Metabolic responses of healthy or prediabetic adults to bovine whey protein and sodium caseinate do not differ. Journal of Nutrition, 145 (3), 467-475. 
[16] Holst, J. J., Gromada, J. (2004). Role of incretin hormones in the regulation of insulin secretion in diabetic and nondiabetic humans. American Journal of Physiology, Endocrinology and Metabolism. 287 (2), E199-206.

[17] Herchuelz, A., Lebrun, P., Boschero, A. C., Malaisse, W. J. (1984). Mechanism of arginine-stimulated $\mathrm{Ca} 2+$ influx into pancreatic B cell. American Journal of Physiology, 246 (1 Pt 1): E38-43.

[18] Sener, A., Best, L. C., Yates, A. P., Kadiata, M. M., Olivares, E., Louchami, K., Jijakli, H., Ladriere, L., Malaisse, W. J. (2000). Stimulus-secretion coupling of arginine-induced insulin release: comparison between the cationic amino acid and its methyl ester. Endocrine, 13 (3), 329-340.

[19] van Loon LJ, Saris WH, Verhagen H, Wagenmakers AJ. Plasma insulin responses after ingestion of different amino acid or protein mixtures with carbohydrate. Am J Clin Nutr. $2000 \mathrm{Jul} ; 72$ (1): 96-105.

[20] Kalogeropoulou D, Lafave L, Schweim K, Gannon MC, Nuttall FQ. Leucine, when ingested with glucose, synergistically stimulates insulin secretion and lowers blood glucose. Metab Clin Exp. 2008 Dec; 57 (12): 1747-52.
[21] Smith, G. I., Yoshino, J., Stromsdorfer, K. L., Klein, S. J., Magkos, F., Reeds, D. N., Klein, S., Mittendorfer, B. (2015). Protein ingestion induces muscle insulin resistance independent of leucine-mediated mTOR activation. Diabetes 64 (5), 1555-1563.

[22] Cherrington, A., Lacy, W., \& Chiasson, J. (1978). Effect of glucagon on glucose production during insulin deficiency in the dog. Journal of Clinical Investigation, 62 (3), 664-677.

[23] Kaneko, K., Shirotani, T., Araki, E., Matsumoto, K., Taguchi, T., Motoshima, H., Yoshizato, K., Kishikawa, H., Shichiri, M. (1999). Insulin inhibits glucagon secretion by the activation of PI3-kinase in In-R1-G9 cells. Diabetes Research in Clinical Practice, 442 (2), 83-92.

[24] Seino, Y., Fukushima, M., \& Yabe, D. (2010). GIP and GLP1, the two incretin hormones: Similiarities and differences. Journal of Diabetes Investigation, 1 (1-2), 8-23.

[25] Frid, A., Nilsson, M., Holst, J., Bjorck, I. (2005). Effect of whey on blood glucose and insulin responses to composite breakfast and lunch meals in type 2 diabetic subjects. American Journal of Clinical Nutrition, 82 (1), 69-75. 